\title{
Plant domestication more rapid under optimizing behavior
}

Serge Svizzero ${ }^{1}(\mathbb{C}$

\begin{abstract}
We assume that early Neolithic cultivators had an optimizing behavior aiming yield maximization and labor efficiency. Then we conduct a hypothetical opti-mization exercise by examining which consequences such behavior would have if applied to the cultivation of Near-Eastern wild cereals, especially on their rate of domestication measured by the frequency of non-shattering seeds. Two stages of the cultivation process are analyzed, the harvest and the processing. The harvest stage requires two strategies, one about the state of ripeness at the harvest and the other about the harvesting method. We demonstrate that under an optimizing behavior most mature seeds are harvested-by combining two technologies, ground collection and sickling - and thus this stage leads to no selective pressure. On the contrary, the pro-cessing stage, from threshing to storage, leads to positive selection when the products of the two harvests are processed separately, a strategy resulting from labor efficiency and risk minimization. Therefore, and from a theoretical point of view, an optimizing behavior tends to support a rapid pathway toward plant domestication, even though the latter is an unconscious outcome of human behavior.
\end{abstract}

Keywords Pre-domestication cultivation - Domestication syndrome $\cdot$ Human behavioral ecology $\cdot$ Pathway to domestication · Near-east $\cdot$ Early neolithic

JEL Codes N5 - Q1 · D01

Serge Svizzero

serge.svizzero@univ-reunion.fr

1 Faculté de Droit et d'Economie, Université de La Réunion, 15 Avenue René Cassin. CS 9003, 97744 Saint Denis, France 


\section{Introduction}

Food production, based on the cultivation of domesticated plants (cereals, pulses...) and the rearing of domesticated animals (sheep, goats...), is the hallmark of the Neolithic revolution. Indeed, it deeply differs from food predation of wild plants and animals which was undertaken by pre-Neolithic hunter-gatherers. The transition between foraging and farming has attracted attention of archaeologists and anthropologists for decades. It is now widely agreed that there were some intermediate stages between these two polar cases. Harris (1989), for instance, assumed the existence of several stages pertaining to the people-plant interaction (Harris and Fuller 2014). Between 'pure' foraging of wild species and agriculture based on domesticated plants, there is an intermediate stage in which wild plants were cultivated. In the academic literature this stage has been labeled "pre-domestication cultivation" (Helbaek 1959), meaning that plants that were morphologically and genetically wild were cultivated (see e.g. Fuller 2007). Thus, the end of this stage - and then the start of agriculture (rather than of cultivation), coincides with the (full) domestication of plants. The latter has occurred independently in several centers around the world (up to 24, according to Purugganan and Fuller 2009). In the Near-East, evidence of pre-domestication cultivation is provided from the 'Pre-Pottery Neolithic A' (PPNA: 9700-8700 c. B.C.; see e.g. Asouti and Fuller (2012, 2013), Goring-Morris and Belfer-Cohen (2016), for a presentation of Early Neolithic chronocultural horizons and subsistence economies in Southwest Asia). It may even had occurred earlier. Indeed a significant presence of weeds, which thrive in disturbed soils such as cultivated fields, in a 23,000-yearold hunter-gatherers' sedentary camp (site of Ohalo II, Israel), provides the earliest evidence of human-disturbed environment at least 11 millennia before the onset of agriculture (Snir et al. 2015).

Scholars have focused their attention on the selective pressures which might have influenced the rate of plant domestication during the Early Neolithic. These influences may have various and multiple origins, such as the biology of plant domestication, resource management strategies, settlement patterns, cultivation and harvesting tech-nologies, food storage, processing and consumption, ritual practices and symbolic behaviors (for an overview, see Asouti and Fuller 2013). We focus our attention on the influences that the harvesting and processing technologies might have had on the dynamics of the domestication rate of Near Eastern cereals. More precisely we wonder which harvesting and processing technologies the early cultivators would have chosen if their behavior was defined as an optimizing behavior. For this purpose, we conduct a hypothetical optimization exercise which nevertheless does not include an empirical validation of our theoretical claims. We define such optimizing behavior in terms of yield maximization and labor cost minimization. We assume that even though their actions (e.g. the choice of the harvesting method) led to the selection of the domestic phenotype and then speeded up the domestication process, cultivators were not con-scious of the selective pressures introduced by their actions. Our aim is thus to provide an answer to the following question: if early cultivators had an optimizing behavior, how rapidly would cereals domestication have occurred? In other words, we want to examine whether an optimizing behavior gives support to a rapid or a protracted transition from foraging to farming. 
By studying, from a theoretical point of view, the pace at which cereals (Pocacae) were initially domesticated during the Early Neolithic period in Southwest Asia, we take part in a current academic debate (Price and Bar-Yosef 2011; Langlie et al. 2014; Fuller et al. 2015; Abbo and Gopher 2017). Indeed two views are opposed in the academic literature, according to the length of the period of time associated with 'pre-domestication cultivation'. One view contends that this period was short, about few decades or at worst few centuries (Abbo et al. 2014a, b; Abbo and Gopher 2017; Tzarfati et al. 2013). It is based on genetic studies of the wild progenitors of domesticates plants (mainly cereals and pulses) as well as on experiments related to cultivation of wild cereals (Zohary 1969, 1984; Ladizinsky 1987). These experiments have shown that under optimal conditions, especially about the harvesting method, the fixation of the main trait defining domestication-namely, for cereals, the elimination of natural seed dispersal - could be achieved in 20-30 years (Hillman and Davies 1990). Additional experiments about the threshing efficiency associated with either wild or domestic cereals have reinforced such view since threshing domestic cereals is labor saving, a feature fostering the selection of the domestic phenotype (Tzarfati et al. 2013). The other view is mainly based on the results of archaeobotany studies and it supports that the domestication of wild plants (mainly cereals and legumes) was a very long process (Tanno and Willcox 2006; Fuller 2007, 2010; Brown et al. 2009; Purugganan and Fuller 2011; Asouti and Fuller 2013; Larson et al. 2014). Rather than being rapid and punctuated, plant domestication is now viewed as a form of an evolutionary process based on mutualism or people-plant interaction (Zeder 2017). Such process, also labeled as "protracted" (and entangled) is assumed to have spanned one (Tanno and Willcox 2006) to four millennia (Larson et al. 2014, p. 6142), such variability resulting from the diversity of species as well as the regions concerned (Arranz-Otaegui et al. 2016).

Even though this debate is about plants and their rate of domestication, it has important implications, beyond plants, on several other debates all pertaining to the transition from foraging to farming. Indeed, if the domestication rate of plants is assumed to be high, then such rapid process of domestication should have encompassed several species at the same time or so, leading to a nutritionally-agronomically balanced crop package, rather than the domestication of only one or two species at the same time. Similarly, if for instance we focus our attention on the NearEast, such domestication should have occurred in a specific and well-defined region, a "core area", where suitable conditions for domestication were met (Bar-Yosef and Meadow 1995; Lev-Yadun et al. 2000; Abbo et al. 2010), rather than occurring independently in multiple and various Near-Eastern regions (Willcox 2005; Fuller et al. 2011; Asouti and Fuller 2012, p. 156, Table 3). Finally, the domestication of a crop package, occurring rapidly and being geographically concentrated should necessary be conscious, i.e. the result of the 'human mind' (Abbo et al. 2014a), rather than the result of unconscious actions. According to the latter, unconscious domestication means that early cultivation of wild plants was a trial and error process (Weiss et al. 2006), some plants (barley, emmer, einkorn, pea, lentil...) being domesticated within the regions they originated from, others (rye, oat) being domesticated later and far from their regions of origins, and some (e.g. Vicia peregrina, Melamed et al. 2008) being abandoned before any domestication occurred. 
As clearly stated by Abbo and Gopher (2017, p. 492), "The various aspects of the two models are intricately interrelated to the extent that deciding on one issue, for example, geographically diffused domestication, will inevitably tip the balance across other debated aspects." In other words, depending on which of the two views about the domestication rate of plants is contented-either a core area-one-event domestication model, or a protracted-multiple origins model-it leads to support a very different narrative about what has been the transition from foraging to farming.

\section{The rate of cereal domestication}

Compared to wild plants, the evolution of domesticated forms of plants involved the selection of traits that were suited to the human rather than the wild environment (Meyer et al. 2012). The domestication of plants resulted in countless forms and varieties, adapted to all kinds of environments and climates. Although plant breeding created such a diversity, even among domesticates which descent from a single wild progenitor, many traits are shared by all of them. Because the types of selected traits were similar across different plant species, this has given rise to the concept of the domestication syndrome (Hammer 1984).

\subsection{The domestication syndrome}

The domestication syndrome can be defined as the characteristic collection of phenotypic traits associated with the genetic change to a domesticated form of an organism from a wild progenitor form. For grain crops, the domestication syndrome usually includes six morphological and physiological traits which are today well defined (Fuller 2007): reduction/elimination of natural seed dispersal, reduction in seed dispersal aids, loss of germination inhibition, increase of seed size, synchronous tillering of plants and ripening of seeds, more compact growth habit.

There exist some controversial issues linked to the definition of the domestication syndrome per se. First, there are some methodological problems in identifying the domestication traits. For instance, all cereals recovered from archaeological excavations are charred (otherwise they would have disappeared) and this leads to difficulties when archaeologists try for instance to measure the increase of grain size, while the trend towards increased seed size is considered as a trait of domestication. Second, although traits associated with domestication are shared by various plant species, the pace at which they have appeared as well as their ordering may differ between plant families. For instance, larger grain size precedes the fixation of the non-shattering ears for cereals, while it is the converse for pulses (Fuller 2007). Third, some authors believe that some traits have appeared or evolved after the pristine domestication episode. Therefore they consider as necessary to distinguish crucial domestication traits from traits that probably evolved post-domestication (Abbo et al. 2014b). 


\subsection{The main domestication trait for cereals}

For cereals, the most important difference which separates domesticated from their wild progenitors is the loss of natural seed dispersal. This means that the dispersal units are shed in the wild species, but remain on the infructescence among the domesticates. The elimination of the natural seed dispersal is considered as the main domestication trait for cereals since it implies that domestic cereals require human intervention — through agriculture - in order to reproduce and survive. In a wild population of cereals, seeds are naturally shattering when ripe, and this allows their natural reproduction (i.e. without human intervention). However it also exists in such population of wild cereals a rare mutant or recessive phenotype, i.e. occurring at very low frequencies, featured by the non-shattering of seeds, even when they are fully ripe. Hillman and Davies (1990, p. 48) have assumed a net forward mutation rate of $10^{-6}$ per generation. In any given population of cereals it is thus possible to measure the rate of domestication as the fraction (or percentage) of the whole population featured by the domestic phenotype, i.e. by non-shattering seeds. When such fraction is growing, the population can be considered as involved in a domestication process. When it is equal or close to one, the population can be considered as domesticated. In the present paper we consider, as Hillman and Davies (1990) did, that the rate of cereal domestication is provided by the ratio of non-shattering seeds present in the whole population.

\section{Selective pressures and domestication}

In addition to the debate about the definition of the domestication syndrome, another controversial issue exists about the selective pressures which have contributed to the domestication of plants. By definition the domestication of plants cannot occur naturally in the wild-i.e. without man intervention. In other words, outside cultivation the domestic mutants are doomed. Thus, in addition to exogenous (or natural) selective pressures (such as climate change) which influence all plants (wild as well as domesticates), the selective pressures at work in the domestication process are linked to human actions (Purugganan and Fuller 2009). The academic literature has identified several selective pressures associated with the behavior of early cultivators, some being directly connected with the cultivation process (e.g. the sowing technique, the harvesting method or the crop processing technique; Fuller et al. 2010; Tzarfati et al. 2013), others being indirectly related or more distant (e.g. the settlement patterns; Asouti and Fuller 2013). The intensity, the direction as well as the relevance of each of these selective pressures are however disputed among scholars (see e.g. Gepts 2004; Allaby 2010; Allaby et al. 2015; Abbo et al. 2014a, b).

In this paper we focus on the domestication of Near-Eastern cereals. Two views exist about the pathway towards domestication, being considered as either rapid or protracted. The rapidity of the domestication process has been confirmed by various experiments related to the cultivation of wild progenitors of domestic plants. Indeed, Hillman and Davies (1990) have shown that the fixation of the main domestication trait for cereals—namely the dominance of non shattering ears—could be reached in 

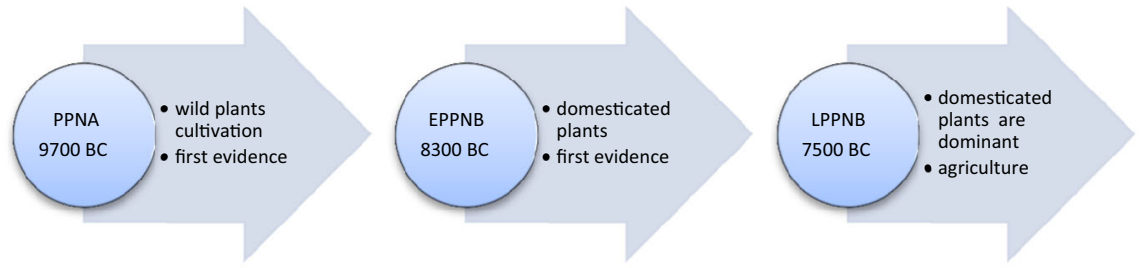

Fig. 1 Major milestones of the pre-domestication cultivation process, according to the protracted model of domestication

20-30 years under optimal conditions, or in 2-4 centuries under conditions less than optimal. This is at odds with the 1-4 millennia assumed for the domestication process under the protracted vision (Tanno and Willcox 2006; Fuller 2007; Purugganan and Fuller 2011; Asouti and Fuller 2012; Larson et al. 2014), which considers a time lag between the onset of pre-domestication cultivation during the PPNA, the initial appearance of non-shattering ears in the EPPNB, and the completion of the biological domestication process with the fixation of non-shattering forms by the LPPNB (as shown in Fig. 1).

\subsection{The focus on the harvesting method and the processing}

Several selective pressures have been identified and studied in the academic literature. As developed below, we focus our attention on two selective pressures related to the harvesting method and the processing since both are directly influenced by the behavior of early cultivators. For other selective pressures we consider simplistic assumptions. For instance we assume that there is no inbreeding between the cultivated plants (wild and domestic) and the wild plants which grow naturally in the vicinity of cultivated fields. Thus the ratio of wild to domestic phenotype in the studied population is not influenced by what happens beyond the borders of the cultivated field. Similarly we assume that early cultivators practiced shifting cultivation, i.e. every season (or year) the seeds were sown on a pristine plot of land. This assumption can be explained by the fact that weeds proliferate in disturbed soils such as cultivated fields. Therefore, it can be more efficient for early cultivators to shift every year to new fields, even though they have to clear them, rather than to incur the cost implied by weeding the same plot every year. Without this assumption, some of the seeds that have shattered on the ground could have survived to predators and mold, and then contributed to the next sowing. Since they have the wild type phenotype, their presence would have modified the ratio of wild to domestic phenotypes in the population.

Concerning the harvesting method, some experiments have shown that the fixation of the main trait defining domestication (the elimination of natural seed dispersal) could be achieved in only 20-30 years (Hillman and Davies 1990). To get this result, cereals must be harvested when mature (and thus some seeds have already shattered or are ready to do so) by sickling (or uprooting), because this technique shakes the ears, i.e. fosters the shattering and then selects against the wild phenotype. Proponents of the protracted view have challenged this conclusion by claiming that, in order to 
avoid losses, cereals were harvested when immature, implying a selection against the domestic type, even if sickle is used (Tanno and Willcox 2006). Others claim that sickles were not used for harvesting cereals during the pre-domestication cultivation period (Fuller 2007; Maeda et al. 2016), and that early cultivators should have preferred the basket beating method because it is more efficient and already used by pre-Neolithic foragers; as a corollary, this technology selects against the domestic phenotype and thus hinders the domestication process.

Concerning the processing, it encompasses several stages, form the threshing to the storage. In the academic literature, most attention has been paid on the threshing stage. For Fuller et al. (2010), the threshing of seeds provided by domestic plants implies additional labor. This need for extra labor expenditure on crop-processing constituted a "labor trap' for early cultivators who, in order to avoid it, should have selected against the domestic phenotype, hindering the domestication process. Tzarfati et al. (2013) reach the opposite conclusion by means of experiments about the threshing efficiency associated with either wild or domestic cereals. For these authors, compared to wild cereals, threshing domestic cereals is labor saving, a feature which should have fostered the selection of the domestic phenotype, and thus speeded up the domestication process.

\section{Optimizing behavior of early cultivators}

A complete description of human behaviors during the prehistoric period is provided by human behavioral ecology (HBE) (Kennett and Winterhalder 2006). Behavioral ecology begins with an optimization premise because, as a result of natural and cultural evolutionary processes, behavior will tend toward constrained optimization (Winterhalder and Kennett 2006, p. 11).

When it is applied to foragers, such as pre-Neolithic hunter-gatherers, this premise means that hunter-gatherers were trying to maximize the net energy implied by their foraging activities. The net energy, expressed in calories, is the difference between the energy provided by the resources that were hunted and gathered, and the energy necessarily spent in order to accomplish these activities. In order to determine the return of any foraging activity, it is thus necessary to measure the net energy obtained during a given period of time. In other words, the yield per unit of time is the relevant indicator of performance for any forager, i.e. the objective function that any forager tries to maximize.

\subsection{Yield maximization of the production process}

When it is applied to farmers, the optimization premise leads to another objective function. Indeed, early cultivators were sedentary or quasi-sedentary, with their settlement located close to the fields they cultivated. The food or energy they were able to produce was therefore dependent on three factors, the area of cultivated land, capital (mainly the seeds used for sowing) and labor. Since the cost of the labor can be expressed in terms of seeds, the production process associated with a given area of land can be expressed as a function of the volume of seeds since they are present as 
output and input. Thus its return is measured - as it is nowadays-by the yield per unit of cultivated land (Hillman and Davies 1990, pp. 69-70; Fuller 2007, p. 904). For instance, it can be measured by the volume (in bushels) of cereals per hectare. Such measure is in fact relevant when the arable land is scarce and that the increase of the agricultural production comes from agriculture intensification, i.e. the use of more inputs per a given unit of land. However arable land was not scarce but plentiful at the commencement of agriculture. Hence early cultivators had the choice to increase their production through either land extension (i.e. extensive agriculture) and/or the use of larger quantities of inputs per unit of land (i.e. intensive agriculture). Therefore, the relevant return of early farming activities could not be the yield per unit of land, but rather the yield per unit of seeds sown. More precisely early cultivators should have tried to maximize the volume of seeds harvested from a given volume of seeds previously sown (Hillman and Davies 1990, p. 57; Willcox 1999, p. 478). It is this objective function that we will assume in the sequel of the present paper.

It should be noted that such a farmer's objective function can be related to the forager's one. Indeed the forager maximizes the yield per unit of time. This is because, in addition to land, labor is the only input of the foraging process. ${ }^{1}$ The return of the foraging process is therefore the yield per unit of time, or more precisely we should said the yield per unit of labor time. For the farmer, and in addition to land, the production process requires two inputs, capital (the seeds used for sowing) and labor, which are not substitutes but perfect complements. Indeed, the cultivation of a certain volume of seeds requires a certain amount of labor time (for tilling, sowing, weeding, irrigating...) and vice versa; spending labor time without seeds for sowing is useless. Labor must then be used in fixed proportions with respect to the volume of seeds sown. Moreover, the amount of labor time used for the cultivation cannot be decided arbitrarily, as for instance a forager do every day. Indeed, for a farmer, working during a week or a month makes no sense. When the cultivation process starts, it requires labor until its end, i.e. during the whole year or so. ${ }^{2}$ Thus for the farmer the relevant length of time is defined by the complete process of production, from sowing to harvesting. Such length can be influenced by the farmer's decision, even though it is mainly determined by exogenous factors (such as the biology of plants, the quality of soils, the climate conditions). Thus, the duration of the cultivation process is fix and likely considered as given from the farmer's point of view. ${ }^{3}$ What is therefore relevant for the farmer is the difference between the inputs of this process, especially the volume of seeds sown, and the output, i.e. the volume of seeds harvested.

\footnotetext{
1 Of course foragers can also use tools, but the latter are not compulsory for foraging.

2 More precisely, at least from the early Winter (time for sowing) to the Summer (time for harvesting) when winter cereals are cultivated. Moreover some work — such as weeding — is also necessary during the fallow period.

${ }^{3}$ Since the duration of the cultivation process is given and fix, i.e. defined by 'a season or a year' because crops can be sown only once a year, the maximization of the yield per unit of time becomes the maximization of the yield per season or per year, i.e. the difference between inputs and output.
} 


\subsection{Labor-efficiency of the processing process}

For farmers, as well as for foragers, their activities do not end with the harvest of plants. Indeed, the harvest of plants simply ends the predation (for foragers) or the production (for farmers) process. However, for both of them, post-harvest activities are necessary until the foraged/produced food can be consumed. These processing activities include threshing, winnowing, storing, pounding and grinding. They all consist in the transformation of what has been harvested from the field and they all require labor as input. Thus, the objective function for the post-harvest activities is defined by the minimization of the labor cost.

To sum up, we assume that early cultivators' objective was twofold. Concerning the production process, from sowing to harvesting, it was to maximize the yield (measured in terms of net grain). Concerning the post-harvest or processing activities, it was to minimize the labor cost, i.e. to achieve (labor) efficiency. ${ }^{4}$

\section{States of ripeness at the harvest and yield maximization}

We distinguish two states of ripeness at the harvest, depending on whether seeds are either unripe or ripe. As a preliminary remark, one should noticed that for cereals it is not the degree of maturity of seeds which is important per se, but rather the state of ripeness of the spikes. Indeed, when the spikes are unripe, i.e. green or immature, the spikelets are not shattering, whatever their phenotype is, wild or domestic. On the contrary, when the spikes are ripe, the spikelets (with the wild phenotype) are progressively shattering with the passage of time. At the end of this process, which may span one to 2 weeks (Cox 2009, p. 6), the spikes are fully ripe, i.e. all seeds with the wild phenotype have shattered. The time span between ripe and fully ripe is variable, according to the species considered, the climate conditions and altitude where cultivation takes place (the time span is lengthened under wetter weather conditions as well as with higher altitude).

From a modern point of view it may seem irrational to harvest green ears. However for early cultivators it was a mean to avoid the losses associated with the shattering seeds when they are ripe at the harvest. There exist some archaeological evidence that cereals have been harvested when unripe (e.g. White and Makarewicz 2012), and this has several implications given our aim.

First, some harvesting methods, such as ground collection of seeds or basket beating (see Sect. 6), are not possible because they require that at least some seeds have shattered or are ready to disarticulate. The harvest can nevertheless be achieved by means of sickling, uprooting the plants or hand-stripping of the spikes.

Second, and as demonstrated through experiments reported by several authors (Anderson-Gerfaud et al. 1991; Willcox 1999, p. 472), a remarkable amount of grains harvested in a fully green state, germinated. Thus harvesting immature grains could

\footnotetext{
${ }^{4}$ Labor efficiency is a measure of how efficiently a given workforce accomplishes a task, when compared to the standard in that industry or setting.
} 
have been very attractive in the Early Neolithic because loss of yield could be avoided and viable grains obtained for the next sowing.

Third, green ears cannot be threshed and processed directly after their harvest. Indeed, before their processing they must be dried, usually sun-dried. This adds more labor costs since some infrastructure should be build (bunches cannot be let on the ground to be sun-dried otherwise the seeds get moldy), the heaps of ears must regularly be turn upside down and constantly monitored to avoid predation from insects, rodents and birds.

Fourth, the yield of such harvest (measured by the volume of seeds harvested compared to the volume of seeds previously sown) is influenced by two opposite factors. On the one hand, since green spikes do not shatter, the cultivator does not have to suffer some losses due to shattering spikelets (it won't be the case if seeds were ripe). On the other hand, green spikes are immature, i.e. they have not reached their maximum weight. Since both factors have opposite influences, it is a priori impossible to say which state of ripeness at the harvest-unripe or ripe-provides the largest yield. Indeed the answer depends on the degree of maturity of unripe seeds (i.e. are they either 'very green' or nearly ripe) as well as on the degree of maturity of ripe seeds (i.e. how many spikelets per spike have already shattered and therefore are lost for the harvester). It should be noted that, as we will develop later in the present paper (Sect. 8), if ground collection of shattered seeds is possible, then no shattered seeds are lost and the answer to the previous question becomes obvious, i.e. harvesting ripe ears provides a larger yield. Even though ground collection of seeds is not considered as possible, the choice between harvesting green or mature seeds is also influenced (beyond aspects related to the direct yield got in both situations) by the labor costs and the risk incurred by the harvester. As shown previously, both are higher when green ears are harvested and thus early cultivators should have been more in favor of harvesting ripe ears.

As an additional remark, White and Makarewicz (2012) have provided evidence, based on archaeobotanical data from el-Hemmeh (Jordan), a settlement site dating to ca. 10850 cal. B.P., that wild barley (Hordeum spontaneum Koch.) was harvested when immature. However, only $22 \%$ of barley rachis internodes specimens possessing a wild morphology show evidence of a forced or "ripped" disarticulation. It is thus impossible from these data to know exactly the percentage of ears which was actually harvested when greens. Besides, we know that synchronous ripening is one of the six traits defining the domestication syndrome. This means, on the contrary, that when cereals were still wild, they get mature at different rates. For instance, Willcox (1999, p. 473) provides a result about uneven ripening of different plants (deduced from experiments about growing wild einkorn): at least a month may elapse between the earliest and the latest maturation in the same field. Therefore, one may interpret the data provided by White and Makarewicz (2012) as follows: the harvest has started when most ears were already ripe, however $22 \%$ of ears were still immature and have nevertheless also been harvested. This case highlights the existence of inherent difficulties when we try to define states of ripeness at harvest. Indeed, the two stages - unripe and ripe-are not discrete but rather are continuous. Moreover, even for a given wild species of cereal, the population is not homogeneous (even under the same growing conditions, seeds do not germinate, flower and ripen at the same time). Even though we are aware of 
these difficulties, and because no simple solution exists (to the current state of our knowledge), we continue to assume in the sequel of the present paper that exist only two states of ripeness at the harvest.

\section{The harvesting methods}

We examine the various harvesting methods of cereals that were doable from a technical point of view during the Early Neolithic in the Near East.

\subsection{Ground collection of seeds}

It requires that spikelets are ripe and that some of them-if not all-have already shattered. As demonstrated by Kislev et al. (2004), such harvesting method is supported by ethnographic evidence (e.g. in Africa) as well as by archaeological evidence. Concerning the latter associated with late Palaeolithic and PPNA sites in the Near East, Kislev et al. (2004) have pointed out that even for shattering ears, the basal spikelet do not shatter, i.e. it remains attached to the culm. Since no basal spikelets and very few unripe grains have been recovered from the excavated sites, these authors deduce that seeds should have been collected from the ground. Since wild cereals usually have very long awns-15 to $20 \mathrm{~cm}$ for wild barley and wild emmer (Kislev et al. 2004, p. 2693) - and that when seeds have shattered, these long awns are pointing upward (due to gravity implied by the weight of the kernel), the harvesters could pick up easily large clumps of spikelets by grasping the upward-pointing awns. ${ }^{5}$

In terms of yield, such method may, from a theoretical point of view, lead to harvesting all seeds that were produced from a given surface area. However such optimistic view must be qualified. One the one hand some seeds are predated by insects and rodents, and given their morphology, wild spikelets have a tendency to rapid self burial into the soil. On the other hand the presence of foliage close to the ground prevents easy gathering of spikelets.

\subsection{Basket beating (or the swinging basket)}

As for ground collection of seeds, the basket beating method requires that seeds are ripe. Ripe seeds that have not yet shattered are harvested either by shaking a basket (the so-called "swinging basket") or by using a paddle to beat the ears over the basket. Beating spikes into a basket is the most time-efficient way to harvest wild grain crops (Hillman and Davies 1990). In other words, this method provides the highest yield per unit of time. However, this method does not provide a high yield in terms of unit area. Indeed, when the basket beating method is applied, some but not all spikelets are fallen into the basket. On the one hand some spikelets have already fallen to the ground, before the harvest, and thus are lost (at least for this harvesting method). On

\footnotetext{
5 Pictures of a clump of spikelets with upward-pointing awns being scarce, especially because wild cereals are hardly cultivated nowadays, the reader can refer to Kislev et al. (2004, p. 2693), Fig. 1.
} 
the other hand, some spikelets (those closer to the basal spikelet) will not disarticulate, even if they are beaten. The only way to harvest them is to undertake additional passes in the upcoming days. However the first of these passes will have led to some trampling of the whole stalks and therefore the yield of the next passes will be seriously lowered (Hillman and Davies 1990, p. 59). Thus it seems more reasonable to consider that if the basket beating method is used to harvest cereals, it is only once (one passes) per season.

\subsection{Hand-plucking or stripping of spikes}

Such method means that the spike or its upper part (if partially mature) is plucked by the harvester. It may be applied when ears are immature or not. However, spikes have to be stripped one by one. Therefore, and as pointed out by Hillman and Davies (1990, pp. 56-57), such method is very inefficient, i.e. it provides a lower yield than any alternative method such as the basket beating or sickling. We do not consider it anymore in the sequel.

\subsection{Sickling or uprooting the plants}

Although they are different, several reasons lead us to consider sickling and uprooting as equivalent methods. They both can be applied to unripe or ripe ears. Compare to other methods, such as ground collection, they both require more human strength and skill. They both provide seeds as output but also a by-product, the straw. When they are applied to ripe ears, they both imply the same drawback: during the harvest, the ears are shaken and therefore a large number of spikelets from wild-type plants are shattering, i.e. they cannot be harvested with such methods and therefore are considered as being lost. Hillman and Davies (1990) found experimentally that a consistently low 40 percent of wild-type seed was recovered by sickling or uprooting. In other words the loss is very important, about $60 \%$ of wild-type seeds are shattering.

Archaeological evidence about the existence of sickle are numerous from the Epipalaeolithic (e.g. during the Natufian period) and thus they predate the predomestication cultivation epoch. However there is a controversy in the academic literature pertaining to whether sickles were used for harvesting either wild cereals or other plants such as reeds used for basketry. In other words, it is disputed to know whether their use was a pre or a post domestication adoption (Fuller 2007; Asouti and Fuller 2013; Maeda et al. 2016). Despite its importance we do not consider farther such controversy because for our purpose, even though sickles were not used, uprooting will have led to the same results. In the sequel we will use the wording "sickling" also for denoting the uprooting method.

\section{Yield maximization and selective pressure with a unique harvesting method}

We have already demonstrated (Sect. 5) that harvesting ripe rather than unripe ears provided a higher yield, at least if the state of ripeness (at the harvest) of ripe ears is 
not too important. All technologies (presented in Sect. 6) can be applied for harvesting ripe ears and so we have to examine which method would be selected by cultivators aiming at the maximization of the yield.

\subsection{Trampling and multiple harvests}

Even though the basket beating method is more efficient than ground collection of seeds, both methods share the same disadvantage. Indeed, to maximize the yield both methods require multiple episodes of harvest. While multiple harvests is an assumption present in the academic literature (see e.g. Fuller 2007, p. 901), we believe it will not have been selected by cultivators willing to maximize their yield. Indeed, and as previously pointed out (Sect. 6), the marginal yield is a decreasing function of the number of harvests or passes since each passes implies trampling and thus leads to additional losses. When people have already walked on seeds fallen on the ground, their collection becomes therefore much more difficult. Similarly, it is much more difficult to apply the basket beating method to stalks that have been trampled during previous passes. While Hillman and Davies (1990, p. 59) were aware of this inconvenient implied by trampling, they do not consider it in their treatment of 'multiple passes'.

By contrast sickling or uprooting are two methods which do not necessitate multiple harvests, i.e. any cultivated field, whatever is its surface, can be harvested through a unique passes. Thus we may deduce that early cultivators would have chosen these methods in order to maximize their yield. It should be noted that Hillman and Davies (1990, pp. 69-70) have reached the same conclusion about the superiority of sickling over beating. They provided various reasons explaining their conclusion, including notably the need "to maximize energy returns per unit area of tilled land" that they deduced from "an extension of optimal foraging theory" (Hillman and Davies 1990, p. $70)$.

\subsection{Straw as a by-product of the harvest}

This conclusion is reinforced by the fact that harvesting with a sickle provides, in addition to the grain, a by-product, the straw. The straw is a valuable product, since it can be used for fire lighting, mud building, and possibly as fodder (Hillman and Davies 1990, p. 70; Asouti and Fuller 2013, p. 319). Impressions of crop processing by-products (especially chaff but also straw used for roof bedding) have been found in abundance in building materials (such as pisé). The abundance of pisé in architecture from the PPNA (Finlayson et al. 2011) seems to confirm the existence of some positive correlation between the development of architecture, sedentism and cereal cultivation. Of course one may argue that the straw could have been harvested separately (later) from the ears, and not necessarily with a sickle. However, since mud building have to be re-build frequently, due to erosion, and if shifting cultivation was practiced, one may infer some degree of causality from the development of architecture and sedentism to the harvesting methods favoring the collection of straw. 


\subsection{The positive selection pressure of sickling}

When ripe cereals are harvested by sickling, it implies a positive selection pressure, i.e. a selective pressure enhancing the rate of domestication (Table 1). Indeed, when ripe, some spikelets have already shattered. In addition, a large proportion (up to 60\%) of spikelets still on the ears are shattering during the harvest because the stalks and the ears are shaken by the harvester. All these lost spikelets are of the wild-type because they have shattered. In other words, non shattering spikelets, which are all harvested, represent a higher proportion of the harvest compared to their proportion in the preharvest population (or equivalently in the seedcorn). Since it is from this harvest that some seeds will be saved in order to be sown the next season, we may expect that the ratio of non-shattering seeds compared to shattering will be increasing season after season. Thus, sickling or uprooting promotes a rapid domestication of cereals which may, under optimal conditions (such as shifting cultivation and the lack of inbreeding) be achieved in 20 years according to Hillman and Davies (1990).

\section{Yield maximization and selective pressure with a mixed harvesting method}

The conclusion of the preceding section is a well known result in the academic literature especially because it supports the view that plant domestication was rapid. As such it has been numerously challenged (Fuller 2007). The choice of the harvesting method has been criticized especially because alternative methods-ground collection or basket beating - provide a negative selection of non-shattering spikelets and therefore hindered the domestication process of plants, the latter being now consistent with the 'protracted' view. As shown by Allaby (2010, p. 936, Fig. 1) the result of Hillman and Davies (1990) is very sensitive to the variation of parameters such as the percentage of seeds that have already shattered when the harvest starts, the percentage of shattered seeds that are not predated and then contribute (naturally) to the next sowing (if cultivation occurs on the same plot). According to the value of these parameters, the selective pressure can be either positive but very low or may even be negative.

\subsection{Shattering seeds: lost or wasted?}

Another aspect present in the paper by Hillman and Davies (1990) which seems impor-tant for us is that because a large fraction of the seeds (up to 60\% according to these authors' experiment) are shattering before and during the harvest (with sickle), then it is assumed that these seeds are lost for the harvester. In fact we should not said "lost" but rather "wasted". How is it possible to assume that early cultivators, whatever the reason(s) explaining why they used a sickle for harvesting cereals, could accept to waste more than half of the seeds present in a field they had cultivated for months?Even though they were not 'perfect maximizers', such a waste seems unlikely to have been tolerated by early cultivators whose life was hard and who are usually described 


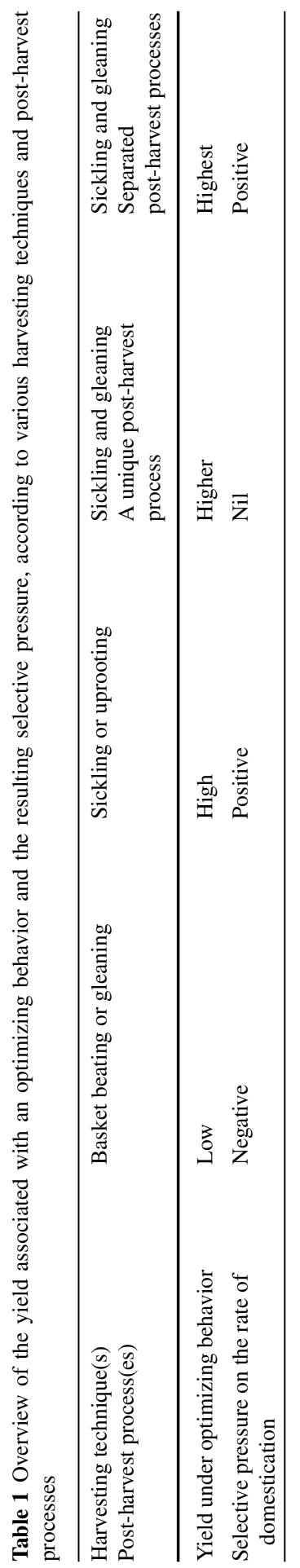


by archaeologists as not well nourished (or less well nourished than when they were hunter-gatherers) (Diamond 1997; Bowles 2011; Berbesque et al. 2014).

\subsection{Mixing ground collection and sickling}

A solution to this puzzle is to assume that these spikelets that had shattered were not wasted but collected from the ground. We recall there exist archaeological evidence that hunter-gatherers had used this harvesting method (Kislev et al. 2004). Moreover, as pointed out by Barnard (2007) and based on contemporary ethnography, huntergatherers who take up farming maintain a hunter-gatherer mind-set (see also Asouti and Fuller 2013). Thus there is no reason to assume that early cultivators neglected the seeds that had shattered while during millennia (and until the very beginning of pre-domestication cultivation), as hunter-gatherers, they had collected them from the ground. We may even note that when the cereal domestication was achieved (and hence all seeds were not shattering), it happened that some stray stalks of cereals were forgotten in the field after the harvest. However they were not wasted but gleaned by peasants, as nicely depicted by Jean-François Millet in his famous oil painting entitled "The Gleaners" (1857). During the Early Neolithic, such collection of shattering spikelets could have been done after the harvest (by sickling) of the ears. However, the longer these seeds remain on the ground, the less numerous there will be for the harvester due to predation (insects, rodents, birds), vermin, fungus or mold. It is thus in the cultivator's interest to shorten as much as possible the delay between the harvest (with sickle) and the ground collection of seeds. In fact the ideal timing is that both intervene at the same time. For that purpose a possible configuration is to combine harvesting with a sickle, performed by a group of persons, and just behind them, to avoid the trampling of the fallen seeds, another group of persons is collecting seeds from the ground. Both harvests at the same time are doable, and moreover they can even be fostered by the division of labor. Indeed, sickling or uprooting requires human strength and/or skill (using a sickle is dangerous) and should be performed by adults. On the contrary the ground collection of seeds requires no human strength or skill and then can be easily performed by children. In other words, this mixed-harvest leads to task-specialization and thus to an improve of the labor efficiency. This is an additional reason explaining why such mixed-harvest maximizes the yield and thus should have been chosen by early cultivators. One consequence of this mixed-harvest is that most seeds (either with the wild or the domestic phenotype) are collected. In other words the percentage of non-shattering spikelets in the harvest, and thus in the next sowing, is very close (if not equal) to the percentage present in the original population: the mixed-harvesting leads to no selective pressure (Table 1).

\section{Efficiency of the post-harvest process and selective pressure}

The previous conclusion holds at the harvest stage of the cultivation process. However this stage is not the final one and the rate of domestication is measured at the end of the post-harvest process by the percentage of domestic phenotype present in the seeds 
used for sowing the next season. Therefore, from the harvest to the next sowing, we have to consider the different intermediate stages featuring the post-harvest process, such as threshing, winnowing, storing, pounding and grinding.

We recall that, as demonstrated in the previous section, the optimizing behavior of cultivators should lead them to combine two harvesting methods at the same time, ground collection and sickling. The post-harvest process is therefore highly dependent on how the products of these two combined but separate harvests are managed. Two cases are possible, depending on whether the products of these two harvests are either merged or kept separate during the post-harvest process. If they are merged as soon as the harvests have ended, then the ratio of domestic phenotype will remain unchanged until the end of the processing. Since it is identical to the ratio present in the initial population used for sowing, then we may conclude that the selective pressures resulting from the harvest and the post-harvest actions are nil (Table 1). The rate of domestication remains, theoretically, the same forever, or if it increases it will result from other selective pressures (not studied in the present paper). Such scenario supports the view of a "protracted pathway towards domestication". As shown in the sequel, it is however less likely to occur under the optimizing behavior of cultivators.

\subsection{Packaging the harvests}

As previously highlighted, a second case is possible and it is when the products of the combined harvest are kept separate during all the stages defining the post-harvest process. We contend that the optimizing behavior of cultivators leads them to realize such separation. Indeed, the post-harvest process requires only one input, namely labor. Thus, the optimizing behavior means that cultivators aim to achieve labor efficiency, i.e. to minimize the labor cost. This separation of the two harvests should occur as soon as the cereals are harvested, i.e. when they are packaged in the field in order to be carried to the processing site. Indeed, one of the two combined harvests, the ground collection of shattered seeds, has led to the collection of seeds with their awns. The packaging of this harvest necessitates the use of baskets for transportation. The second of the two combined harvests, the use of sickle, has led to the collection of stalks with their ears. In order to be brought, such harvest can be conditioned as a pack hold between the arms or as a bale of straw. In any case, a unique packaging used when the harvests were merged is clearly inefficient compared to two separate packaging.

\subsection{Pre-threshing and threshing}

The next stage of the processing is threshing and here again it is efficient to keep separate the products of the two harvests. Indeed, the spikelets with their awns, collected from the ground, can be threshed as soon as the awns are removed (for instance by brief firing). By comparison, the product of the other harvest requires two additional pre-threshing operations: the stalks have to be separated from the ears, 
and the (wild and domestic) spikelets have to be disarticulated (by hand) from the spike. $^{6}$

\subsection{Purposes and timing of the storages}

Once the awns have been removed, the seeds can be threshed, winnowed and then stored. The storage may have two different purposes. On the one hand, seeds are stored to be consumed later, and this requires that at first they will be pounded and grinded. On the other hand some seeds are stored in order to be sown during the next season. While the latter are necessarily stored for several months (at least from Summer to Early Winter, for winter crops), the former must not be stored during such a long period. Thus, any wise cultivator will store for several months (i.e. for the next sowing) the healthier seeds, i.e. the seeds which have a better chance to avoid insects, vermin and mold while they are stored. This risk minimization gives an additional incentive to the cultivator to separate the products of the two combined harvests, as well as all the different stages pertaining to their processing, including their storage.

Indeed, the seeds which have been collected from the ground have remained a period of time on the ground or very close to it. This period can be hours or days (and nights), and obviously it is longer for spikelets that have shattered first. During this period of time, the seeds, only protected by their glumes, have been in close contact with the insects and the moisture of the soil. Thus, these seeds are vulnerable, i.e. they have better chance to get moldy when stored. To minimize this risk, the cultivator has incentives to process these seeds first (compared to the seeds provided by the other harvest), to store them during the shortest period of time, i.e. to consume them first. The latter implies that all these seeds should be consumed, i.e. none of them should be kept for the next sowing. The way the product of this harvest is managed has consequences on the timing and the purposes of the storage of the product of the second harvest.

Concerning the other harvest, done with sickle, the product are seeds (when straw has been removed), with their glumes, within their spikelets and the latter being firmly attached to the spike. Such natural protection of the seeds is valuable. Therefore, once the stalks are removed from the ears, it is not necessary to pursue immediately the pre-threshing (disarticulation of the spikelets) and the threshing process. Indeed, the cultivator has incentives to store the spikes rather than the seeds, because the former have better natural protection. Thus the timing of threshing-storing operations is inversed. Once the short-term storage provided by the other harvest will be completely consumed, then this long-term storage will be used, for consumption as well as for the next sowing. Since this long-term storage encompasses the ears that have been gathered with a sickle, it contains a higher ratio of domestic phenotype compared to the initial population. Thus, the separation of the post-harvest process, resulting from

\footnotetext{
6 It is worth noting that while Tzarfati et al. (2013) aim to compare the threshing time and efficiency associated with domestic cereals and their wild progenitors, they do not include in their experiments these two pre-threshing activities. Their inclusion could contradict the conclusion of these authors and support the opposite idea that threshing (a growing number of) domestic phenotype implies a labor trap and therefore a negative selective pressure, as developed by Fuller et al. (2010).
} 
an optimizing behavior motivated by labor efficiency and risk minimization, leads to a positive selective pressure. In other words, while the optimizing behavior at the harvesting stage implied no selective pressure, it implies a positive selective pressure during the post-harvest stage (Table 1).

\section{Concluding comments}

When they have initiated the cultivation of wild plants, the cultivators of the Early Neolithic clearly were willing that it contributed to their diet. If such intention is obvious, their economic behavior, i.e. the way they managed the cultivation process, remains a puzzle. We have extended to early cultivators the premise of Optimal Foraging Theory by assuming that they had an optimizing behavior, aiming at yield maximization and labor efficiency. Then we have examined, for each stage of the cultivation process (from sowing to the harvest) and of the processing (from threshing to storage), what would have been the strategy decided under an optimizing behavior. This has provided us a sequence of optimal decisions: harvesting ripe ears by combining at the same time ground collection of seeds and sickling, and keeping separate during all the post-harvest stages the product of these two harvests. Then we have demonstrated that this sequence of optimal decisions was leading to selection against the wild phenotype, i.e. was increasing the rate of cereal domestication.

Our main result is thus that an optimizing behavior gives support to a rapid pathway towards domestication of cereals. The introduction of such assumption, and the consequences it implies, constitutes a real departure from what is usually highlighted in the debate about the protracted vs rapid transition towards plant domestication. Indeed, the selective pressures at the centre of this controversial issue are either exogenous to human action, e.g. related to the biology of plant species or the climate, or endogenous. For the latter, various assumptions used in the academic literature are about the cultivation and harvest technologies, the processing and consumption, or the food storage. However, none of these various assumptions are justified by any reference to what could have been the economic behavior of early Neolithic cultivators. By assuming yield maximization, all these assumptions about human actions are now considered as decision variables, i.e. as the result of an optimizing behavior. Then, by introducing an optimizing behavior, we have shed new light on the debate about the pace of the plant domestication process.

In addition to the state of ripeness at the harvest, the harvesting techniques and the processing stages, several other sources of selective pressures exist but were not investigated in the present paper, and they may have played a significant role under an optimizing behavior. Some of these, such as the frequency at which shifting cultivation occurred, could also have been influenced by the economic behavior of early cultivator, showing that the importance of the latter should be taken into account systematically.

Acknowledgements The author thanks an anonymous referee for his comments and suggestions. The usual caveat applies. 


\section{References}

Abbo, S., \& Gopher, A. (2017). Near eastern plant domestication: A history of thought. Trends in Plant Science, 22(6), 491-511.

Abbo, S., Lev-Yadun, S., \& Gopher, A. (2014a). The 'human mind' as a common denominator in plant domestication. Journal of Experimental Botany, 65, 1917-1920.

Abbo, S., Pinhasi van-Oss, R., Gopher, A., Saranga, Y., Ofner, I., \& Peleg, Z. (2014b). Plant domestication versus crop evolution: A conceptual framework for cereals and grain legumes. Trends in Plant Science, 19, 351-360.

Abbo, S., Lev-Yadun, S., \& Gopher, A. (2010). Agricultural origins: centers and non-centers; a Near Eastern reappraisal. Critical Reviews in Plant Sciences, 29, 317-328.

Allaby, R. (2010). Integrating the processes in the evolutionary system of domestication. Journal of Experimental Botany, 61(4), 935-944. https://doi.org/10.1093/jxb/erp382.

Allaby, R., Kitchen, J. L., \& Fuller, D. Q. (2015). Surprisingly low limits of selection in plant domestication. Evolutionary Bioinformatics, 11(S2), 41-51. https://doi.org/10.4137/EBO.S33495.

Anderson-Gerfaud, P. J., Deraprahamian, G., \& Willcox, G. (1991). Les premières cultures de céréales sauvages et domestiques primitives au Proche-Orient néolithique: résultats préliminaires d'expériences à Jalès (Ardéche). Cahiers Euphrate, 5-6, 191-232.

Arranz-Otaegui, A., Colledge, S., Zapata, L., Teira-Mayolini, L. C., \& Ibáñez, J. J. (2016). Regional diversity on the timing for the initial appearance of cereal cultivation and domestication in southwest Asia. PNAS, 113(49), 14001-14006.

Asouti, E., \& Fuller, D. (2012). From foraging to farming in the southern Levant: The development of Epipalaeolithic and Pre-pottery Neolithic plant management strategies. Vegetation History and Archaeobotany, 21, 149-162.

Asouti, E., \& Fuller, D. (2013). A contextual approach to the emergence of agriculture in Southwest Asia: Reconstructing early Neolithic plant-food production. Current Anthropology, 54(3), 299-345.

Barnard, A. (2007). From Mesolithic to Neolithic modes of thought. In A. Whittle \& V. Cummings (Eds.), Going over: The Mesolithic-Neolithic transition in north-west. Europe (Proceedings of the British Academy 144) (pp 5-19). London: British Academy.

Bar-Yosef, O., \& Meadow, R. H. (1995). The origins of agriculture in the Near East. In T. D. Price \& A. B. Gebauer (Eds.), Last hunters-first farmers: New perspectives on the prehistoric transition to agriculture (pp. 39-94). Santa Fe, NM: School of American Research.

Berbesque, J. C., Marlowe, F. W., Shaw, P., \& Thompson, P. (2014). Hunter-gatherers have less famine than agriculturalists. Biology Letters, 10, 20130853. https://doi.org/10.1098/rsbl.2013.0853.

Bowles, S. (2011). Cultivation of cereals by the first farmers was not more productive than foraging. PNAS, 108(12), 4760-4765.

Brown, T. A., Jones, M. K., Powell, W., \& Allaby, R. G. (2009). The complex origins of domesticated crops in the Fertile Crescent. Trends in Ecology \& Evolution, 24(2), 103-109. https://doi.org/10.1016/j.tree. 2008.09.008.

Cox, T. S. (2009). Crop domestication and the first plant breeders. In S. Ceccarelli, E. P. Guimaraes, \& E. Weltizien (Eds.), Plant breeding and farmer participation (pp. 1-26). Rome: U.N. Food and Agriculture Organization.

Diamond, J. (1997) The worst mistake in the history of the human race. Discover Magazine, pp. 64-66.

Finlayson, B., Mithen, S. J., Najjar, M., Smith, S., Maričević, D., Pankhurst, N., Yeomans, L. (2011). Architecture, sedentism, and social complexity at Pre-Pottery Neolithic A WF16, Southern Jordan. PNAS, 108(20), 8183-8188.

Fuller, D. Q. (2007). Contrasting patterns in crop domestication and domestication rates: recent archaeological insights from the Old World. Annals of Botany, 100, 903-924.

Fuller, D. Q. (2010). An emerging paradigm shift in the origins of agriculture. General Anthropology, Bulletin of the General Anthropology Division, 17(2), 1-12.

Fuller, D. Q., Allaby, R. G., \& Stevens, C. (2010). Domestication as innovation: The entanglement of techniques, technology and chance in the domestication of cereal crops. World Archaeology, 42, 13-28.

Fuller, D. Q., Willcox, G., \& Allaby, R. G. (2011). Cultivation and domestication had multiple origins: arguments against the core area hypothesis for the origin of agriculture in the Near East. World Archaeology, 43(4), 628-652. 
Fuller, D. Q., Kingwell-Banham, E., Lucas, L., Murphy, C., \& Stevens, C. (2015). Comparing pathways to agriculture. Archaeology International, 18, 61-66. https://doi.org/10.5334/ai.1808.

Gepts, P. (2004). Crop domestication as a long term selection experiment. Plant Breeding Review, 24, 1-44.

Goring-Morris, A. N., \& Belfer-Cohen, A. (2016). The appearance of the PPNA in the Levant: Sudden? Gradual? And where from? In Ü. Yalçın (Ed.) Anatolian Metal VII-Anatolia and neighbours 10.000 years ago (pp. 185-198). Bochum: Der Anschnitt - Zeitschrift für Kunst und Kultur im Bergbau, Beiheft 31.

Hammer, K. (1984). Das Domestikations syndrom. Die Kulturpflanze, 32, 11-34.

Harris, D. R. (1989). An evolutionary continuum of people-plant interaction. In D. R. Harris \& G. C. Hillman (Eds.), Foraging and farming: the evolution of plant exploitation (pp. 11-26). London: Routledge.

Harris, D. R., \& Fuller, D. Q. (2014). Agriculture: definition and overview. In C. Smith (Ed.), Encyclopedia of global archaeology (pp. 104-113). New-York: Springer.

Helbaek, H. (1959). Domestication of food plants in the old world: Joint efforts by botanists and archeologists illuminate the obscure history of plant domestication. Science, 130(3372), 365-372.

Hillman, C. G., \& Davies, M. S. (1990). Domestication rates in wild type wheats and barley under primitive cultivation. Biological Journal of the Linnean Society, 39, 39-78.

Kennett, D. J., \& Winterhalder, B. (Eds.). (2006). Behavioral ecology and the transition to agriculture. Berkeley: University of California Press.

Kislev, M. E., Hartmann, A., \& Weiss, E. (2004). Impetus for sowing and the beginning of agriculture: Ground collecting of Wild Cereals. PNAS, 101, 2692-2695.

Ladizinsky, G. (1987). Pulse domestication before cultivation. Economic Botany, 42, 60-65.

Langlie, B. S., Mueller, N. G., Spengler, R. N., \& Fritz, G. J. (2014). Agricultural origins from the ground up: archaeological approaches to plant domestication. American Journal of Botany, 101(10), 1601-1617.

Larson, G., Piperno, D. R., Allaby, R. G., Purugganan, M. D., Andersson, L., Arroyo-Kalin, M., Barton, L., Vigueira, C. C., Denham, T., Dobney, K., Doust, A. N. (2014). Current perspectives and the future of domestication studies. PNAS, 111(17), 6139-6146.

Lev-Yadun, S., Gopher, A., \& Abbo, S. (2000). The cradle of agriculture. Science, 288, 1602-1603.

Maeda, O., Lucas, L., Silva, F., Tanno, K. I., \& Fuller, D. Q. (2016). Narrowing the harvest: Increasing sickle investment and the rise of domesticated cereal agriculture in the Fertile Crescent. Quaternary Science Reviews, 145, 226-237.

Melamed, Y., Plitzmann, U., \& Kislev, M. E. (2008). Vicia peregrina: an edible early Neolithic legume. Vegetation History and Archaeobotany, 17, 29-34.

Meyer, R. S., DuVal, A. E., \& Jensen, H. R. (2012). Patterns and processes in crop domestication: An historical review and quantitative analysis of 203 global food crops. New Phytologist, 196, $29-48$. https://doi.org/10.1111/j.1469-8137.2012.04253.x.

Price, T. D., \& Bar-Yosef, O. (2011). The origins of agriculture: new data, new ideas. Current Anthropology, 52, S163-S174.

Purugganan, M. D., \& Fuller, D. Q. (2009). The nature of selection during plant domestication. Nature, $457,843-848$.

Purugganan, M. D., \& Fuller, D. Q. (2011). Archaeological data reveal slow rates of evolution during plant domestication. Evolution, 65, 171-183.

Snir, A., Nadel, D., Groman-Yaroslavski, I., Melamed, Y., Sternberg, M., Bar-Yosef, O., Weiss, E. (2015). The origin of cultivation and proto-weeds, long before Neolithic farming. PLoS ONE, 10(7), e0131422. https://doi.org/10.1371/journal.pone.0131422.

Tanno, K. I., \& Willcox, G. (2006). How fast was wild wheat domesticated? Science, 311, 1886.

Tzarfati, R., Saranga, Y., Barak, V., Gopher, A., Korol, A. B., \& Abbo, S. (2013). Threshing efficiency as an incentive for rapid domestication of emmer wheat. Annals of Botany, 112, 829-837.

Weiss, E., Kislev, M. E., \& Hartmann, A. (2006). Autonomous cultivation before domestication. Science, 312, 1608-1610.

White, C. E., \& Makarewicz, C. A. (2012). Harvesting practices and early Neolithic barley cultivation at el-Hemmeh, Jordan. Vegetation History and Archaeobotany, 21, 85-94.

Willcox, G. (1999). Agrarian change and the beginnings of cultivation in the Near East: evidence from wild progenitors, experimental cultivation and archaeobotanical data. In C. Gosden \& J. Hather (Eds.), The prehistory of food: appetites for change (pp. 468-490). New-York: Routledge.

Willcox, G. (2005). The distribution, natural habitats and the availability of wild cereals in relation to their domestication in the Near East: Multiple events, multiple centres. Vegetation History and Archaeobotany, 14, 534-541. 
Winterhalder, B., \& Kennett, D. J. (2006). Behavioral ecology and the transition from hunting and gathering to agriculture. In D. J. Kennett \& B. Winterhalder (Eds.), Behavioral ecology and the transition to agriculture (pp. 1-21). Berkeley: University of California Press.

Zeder, M. A. (2017). Domestication as a model system for the extended evolutionary synthesis. Interface Focus, 7, 20160133. https://doi.org/10.1098/rsfs.2016.0133.

Zohary, D. (1969). The progenitors of wheat and harley in relation to domestication and agricultural dispersal in the Old World. In P. J. Ucko \& C. W. Dimbleby (Eds.), The domestication and exploitation of plants and animals (pp. 47-66). London: Duckworth.

Zohary, D. (1984). Modes of evolution of plants under domestication. In W. F. Grant (Ed.), Plant biosystematics (pp. 579-586). Montreal: Academic Press. 